\title{
Role of hydrodissection in septoplasty: a modern outlook
}

\author{
Saai Ram Thejas, Rajamohan Ganganamoni \\ RVM Institute of Medical Sciences, Mulugu Mandal, Siddipet District, Telangana, India
}

\begin{abstract}
BACKGROUND. Septoplasty is an age-old surgery performed mainly for a deviated nasal septum. Various methods have been described and the surgery is left to the choice of the surgeon. Traditional septoplasty has taken a back seat in the modern era because of various complications. Newer techniques are being practiced owing to better outcomes. Hydrodissection for septal flap elevation has been both criticized and appreciated because of multiple reasons. In this study, we have used this technique in practice and evaluated its outcome.
\end{abstract}

MATERIAL AND METHODS. 184 patients with Deviated Nasal Septum (DNS) were evaluated. 82 in Group 1 underwent conventional septoplasty with Freer's elevator and 102 in Group 2 underwent septoplasty with hydrodissection using Normal Saline (NS). Time taken to perform flap elevation, status of the mucoperichondrial flap intra-operatively and scoring of adhesions 4 weeks postoperatively were the parameters of study.

RESULTS. 19 out of 82 cases had tears in the mucoperichondrium in Group 1, amounting to $23.17 \%$. 11 patients out of 102 had tears in Group 2, amounting to $10.78 \%$. The average time taken to perform the flap elevation was 11 minutes in Group 1 and 5 minutes in Group 2. Average score in crusting/adhesions was 0.66 in Group 1 and 0.53 in Group 2, out of a possible 4.

CONCLUSION. Hydrodissection in septoplasty for the elevation of the mucoperichondrium and mucoperiosteum is a useful step in surgery provided that it is performed using Normal Saline. It is easy to perform, inexpensive and completely safe to perform without any serious complications.

KEYWORDS: hydrodissection, septoplasty, deviated nasal septum, normal saline.

\section{INTRODUCTION}

Septal deviation is among the common causes of nasal obstruction and a significant problem in practice $^{1}$. The surgical correction of the deviated nasal septum is a very common ENT-operation in adults ${ }^{2}$. Various authors have described their own methods of Septoplasty ${ }^{3-7}$.

The surgical procedure of septoplasty involves the elevation of the mucoperichondrium from the cartilage of the septum followed by the mucoperiosteum. This is a vital step of the surgery and, if this step is properly performed, the mucosal flap remains intact and the blood loss is also reduced to a minimum.

Numerous classic textbooks advocate hydrostatic subperichondrial dissection as a useful step in septoplasty $^{8-10}$. Some surgeons even consider the first injection "as the key step in elevating the flaps, as the injection itself must occur in the correct plane with high pressure to elevate the perichondrium" ${ }^{11}$. This technique has also been questioned on theoretical grounds ${ }^{12}$.
Usually, the agent used in flap elevation is $2 \% \mathrm{Li}$ docaine with 1 in 100000 Adrenaline. Excessive use of this has been reported to cause complications ${ }^{13}$.

Generalized concavity / convexity of the cartilaginous part of the nasal septum has been proved to be the most frequent type of deviation. A conventional approach to correct the deviated septum involves the separation of the bony-cartilaginous junction. At this anatomical point, there is a very high chance that the mucoperichondrial flap tears. A tear in one side usually does not need immediate correction, but in cases of large spurs, the corresponding area on the opposite side also becomes prone to tears. This can cause septal perforations, which is a common occurrence in regular practice.

Hydrodissection is defined as pressure insufflation of fluid into a space with subsequent increase in hydrostatic pressure that separates the various planes between tissues. The principle is based on the pathophysiology of nasal septal haematoma. It is on the lines that the undue collection of blood increases the

Corresponding author: Dr. Saai Ram Thejas, Department of Otorhinolaryngology and Head \& Neck Surgery, RVM Institute of Medical Sciences, Mulugu Mandal, Siddipet District, Telangana, India - 502279 


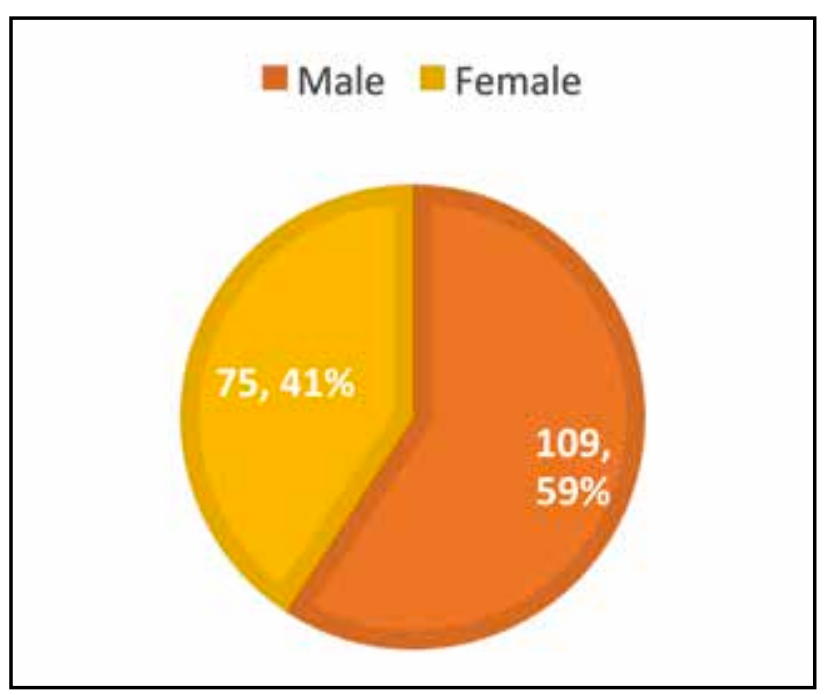

Figure 1. Distribution based on gender.

pressure in the subperichondrial space and thus separates the perichondrium from the nasal septum.

Posterior septal perforations are asymptomatic, but anterior perforations almost always cause whistling noises, dryness and epistaxis. These need to be avoided while performing surgery. Thus, a proper hydrodissection becomes even more necessary. Trauma caused while elevating with an instrument is far more significant than the same caused by a liquid.

In our study, we have used a different type of hydrodissection in which we have replaced the local anaesthetic and vasoconstrictor solution with Normal Saline. As the various complications noted come because of Adrenaline, it has not been used in our study. Time taken to perform flap elevation, status of the mucoperichondrial and mucoperiosteal flaps and crusting post-operatively were the parameters of study.

\section{MATERIAL AND METHODS}

We performed a prospective clinical study on 184 patients with deviated nasal septum with indication for surgical approach.

The preoperative assessment consisted in clinical examination, diagnostic nasal endoscopy (DNE) and computed tomography (CT) scan. Patients were counselled for surgery and proper written consent was taken for the surgical procedure.

We included in our study group patients aged 18-45, with nasal septal deviation, with or without spur, who gave their informed consent for surgery. All the patients signed a written agreement to be part of the study.

We excluded from our study the patients with

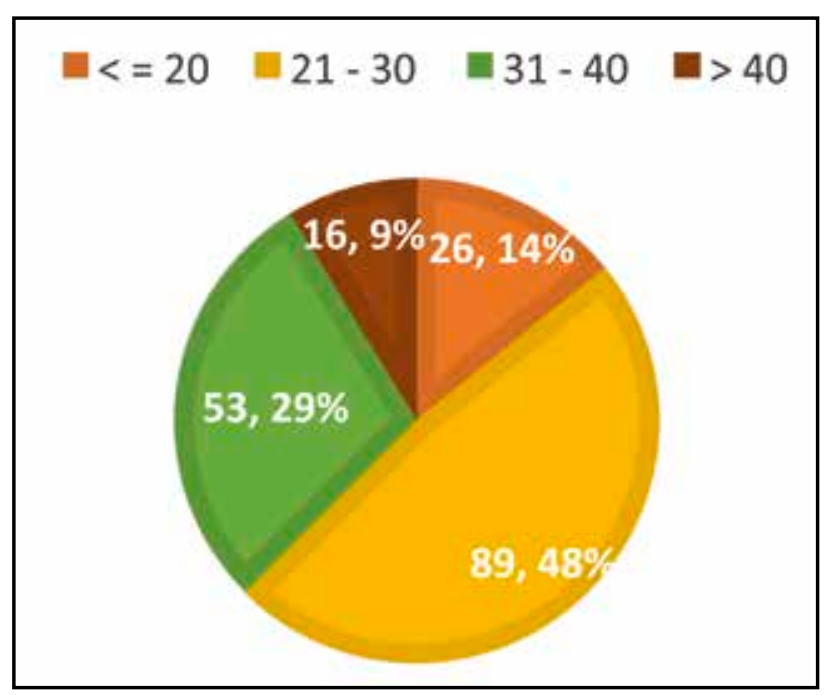

Figure 2. Distribution based on age, in years.

co-morbidities, patients with septal deviation predisposing to sinusitis, extremes of age or other space occupying lesions of the nasal cavity. Also, patients unfit for general anaesthesia were not included in the clinical study.

All the patients were randomly divided into two groups. Group 1 consisted of eighty-two (82) patients and they underwent septoplasty with conventional elevation of the mucoperichondrium with Freer's elevator. Group 2 consisted of one hundred and two (102) patients and they underwent septoplasty with hydrodissection using Normal Saline and extension of the flap with Freer's elevator.

The two types of surgical approach were compared, using several parameters, such as the time taken to perform the step of mucoperichondrial and mucoperiosteal flap elevation, condition of the mucoperichondrial and mucoperiosteal flaps on both sides and crusting and adhesions before and after surgery.

In order to measure the time taken to perform the step of mucoperichondrial and mucoperiosteal flap elevation, the timer was started as soon as the hemitransfixion incision was given. It went on till it was confirmed by both the surgeon and the assisting surgeon that the flaps on both sides were elevated and it was okay to proceed to the next step.

For the condition of the mucoperichondrial and mucoperiosteal flaps on both sides, the flaps were assessed with an endoscope to look for any signs of trauma or tear.

A scoring chart was prepared to assess the crusting and adhesions before and after surgery. LundMackay scoring system was used for reference and a modified scale was developed ${ }^{14}$. Presence of crusting was given 1 point for each side. Presence 


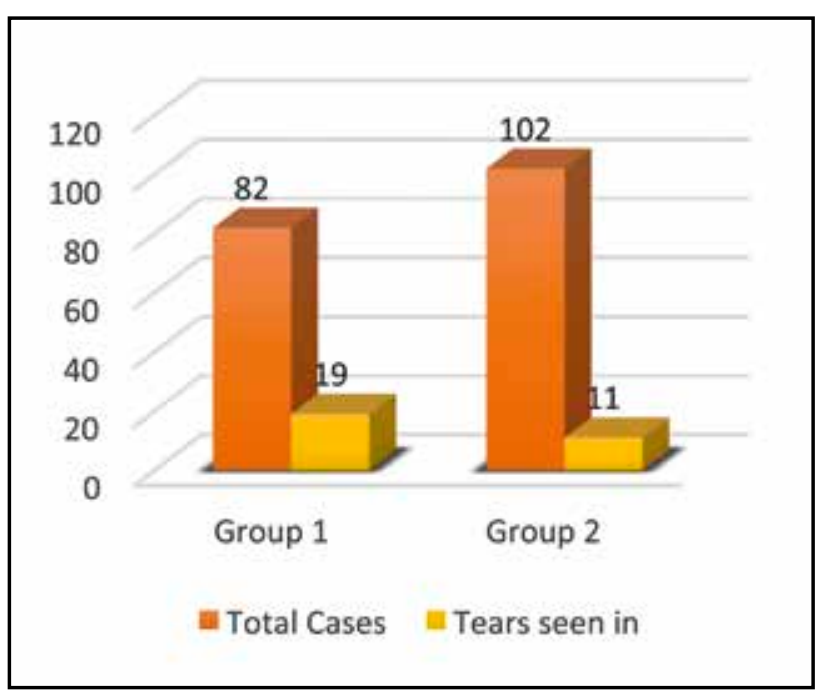

Figure 3. Presence of mucosal tears in both groups.

of adhesion / synechiae was given 1 point for each side. Thus, a maximum score of 4 could be reached. These were assessed at the end of 4 weeks.

All the surgeries were performed by experienced surgeons and under hypotensive general anaesthesia. The step of hydrodissection with Normal Saline was performed by the same surgeon in all cases. This helped to avoid bias and aided in better outcome. A 0-degree Hopkins Rod was used whenever necessary. Care was taken to achieve the subperichondrial dissection. Lidocaine and Adrenaline were not used. In all the patients, the wound was closed with 3-0 Catgut sutures and both nasal cavities were packed with Framycetin gauze in the form of a step ladder anterior nasal pack.

The nasal pack was removed after 24 hours. All patients were asked to start nasal douching with Normal Saline 6 times per day for the next 7 days. Decongestant Nasal Drops were used for 7 days. Follow-up was performed weekly and findings were noted after 4 weeks.

All statistical analyses were performed by using the SPSS Statistics 19 Software for Windows (IBM Corp., Armonk, NY, USA). Samples were compared by a

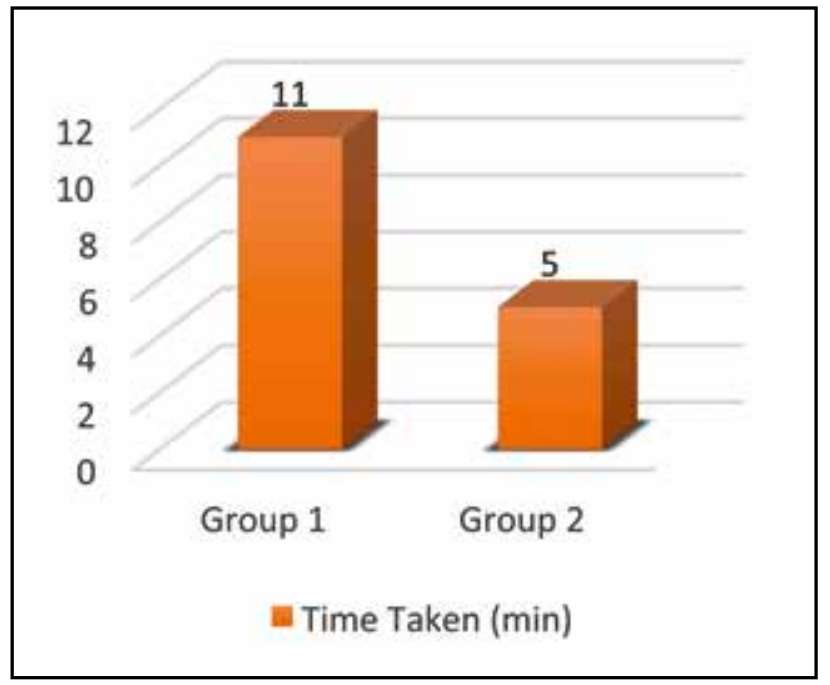

Figure 4. Time taken for flap elevation in both groups.

Paired T-test. A $p$-value $<0.05$ was considered statistically significant. The confidence interval was set at $95 \%$.

\section{RESULTS}

Out of the 184 patients, 109 were male and 75 were female (Figure 1). The youngest patient was 18 years old and the oldest patient was 48 years old (Figure 2). A total of 19 out of 82 cases had tears in the mucoperichondrium in Group 1, amounting to $23.17 \% .11$ patients out of 102 had tears in the mucoperichondrium in Group 2, amounting to $10.78 \%$ (Figure 3). As this assessment was performed intra-operatively, any risk of septal perforation was evaluated immediately. In 9 cases out of 184 , there was evidence to prove that a perforation would have formed in the post-operative period and the same was corrected with a cartilage graft at the site of the tear. The average time taken to perform the flap elevation in Group 1 was 11 minutes and in Group 2 was 5 minutes (Figure 4). Average score in crusting/adhesions was 0.66 in Group 1 and 0.53 in Group 2 out of a possible 4 (Table 1 ).

Table 1. Paired Sample Statistics for presence of crusting/adhesions post-operatively in both groups.

\begin{tabular}{cccccccc}
\hline & \multicolumn{9}{c}{ Paired Differences } & t & Sig. & Correlation \\
\cline { 2 - 5 } & Mean & $\begin{array}{c}\text { Standard } \\
\text { Deviation }\end{array}$ & $\begin{array}{c}\text { Standard } \\
\text { Error Mean }\end{array}$ & $\begin{array}{c}\text { 95\% confidence interval of } \\
\text { the difference }\end{array}$ & Lower & Upper & 0.001 \\
\hline $\begin{array}{c}\text { Crusting/Adhesion in } \\
\text { Group 1 vs Group 2 }\end{array}$ & 0.14 & 0.57 & 0.04 & 0.06 & 0.22 & 3.34 & 0.74 \\
\hline
\end{tabular}




\section{DISCUSSIONS}

Septoplasty is one of the oldest, yet very important, surgical procedures performed in the regular practice of an Otorhinolaryngologist. It is very important to note that the procedure has evolved from being limited to anterior deviations to the modern era where the advent of CTs and endoscopes has made it possible to treat large spurs and posterior deviations.

The hydrodissection for flap elevation was first described by J. Tahery et al in $2004^{15}$. They advocated placing the needle containing the agent a few millimetres underneath the perichondrium and injecting $2 \mathrm{ml}$ of xylocaine with adrenaline, which facilitates raising the right plane. The solution is applied with pressure and with the aim of hydrodissecting the subperichondrial plane with lesser trauma.

Dubach, Mantokoudis et al., in 2010, observed that excessive septal infiltrations by local anaesthetics and adrenalin formed an unreliable dissection technique. They suggested that a careful administration of only small single doses adequate for haemostasis and local anaesthesia minimizes the risk of side effects. They concluded that the technique helps in allowing preservation of the soft tissue envelope in a relatively avascular zone ${ }^{16}$.

Various studies have shown that the mucosal incision must be properly anterior to allow wide access to the deformity. This is because the skin over which the incision is placed helps in protecting damage to the flap by instrumentation. It has also been mentioned that a good septal surgery (confirmed by DNE for complications) can absolutely help in improvement in the quality of life of all the patients ${ }^{17,18}$.

In Group 1, the number of cases in which mucosal tears were noticed stood at $23 \%$, whereas the same value in Group 2 stood at $11 \%$. This can be attributed to the fact that flap elevation without hydrodissection required more instrumentation and pull. The same also explains why that particular step took 11 minutes in Group 1 and 5 minutes in Group 2 on an average. Thus, it is evident that hydrodissection provides better surgical field and reduces the time taken for surgery. Therefore, post-operative crusting at the surgical field and adhesions also were lesser in Group 2 than in Group 1. Student T-Test statistics proved that the postoperative adhesions and crusting were lesser in Group 2 than in Group 1.

Since there was a lot of confusion about the relevance of this technique in literature, this study was taken up to study in detail its usefulness. The study has proven to be statistically significant and helps understand more about hydrodissection. The amount of NS used for flap elevation was also noted and it ranged from $8 \mathrm{ml}$ to $22 \mathrm{ml}$, based on the extent and location of the deviation. No serious complications were noted in the study.

The advantages of this method include less operating time, better nasal cavity picture post-operatively and lesser complications.

The disadvantages include the fact that it is hard to use it in case of posterior deviations and bony spurs where the periosteum is prominent. The elevation of the mucoperiosteum is much harder to perform than that of the mucoperichondrium.

\section{CONCLUSIONS}

Hydrodissection in septoplasty for the elevation of the mucoperichondrium and mucoperiosteum is a useful step in surgery provided that it is performed using Normal Saline. It is easy to carry out, does not require any special tools, inexpensive and completely safe to perform without any serious complications. It can be used as a stand-alone technique or with extension with Freer's elevator.

Acknowledgement: We would like to thank Meenakshi Medical College \& Hospital, Kanchipuram, Tamil Nadu and RVM Institute of Medical Sciences, Siddipet District, Telangana for helping us with the study in terms of acquiring cases and access to various materials.

Conflict of interest: The authors have no conflict of interest.

Contribution of authors: All authors have equally contributed to this work.

Compliance with ethical standards: All patients have given their consent for surgery and to be part of the study. The study has been performed in accordance with the ethical standards laid down by the 1964 Declaration of Helsinki.

\section{REFERENCES}

1. Fettman N, Sanford T, Sindwani R. Surgical management of the deviated septum: techniques in septoplasty. Otolaryngol Clin North Am. 2009;42(2):241-52, viii. DOI: 10.1016/j.otc.2009.01.005.

2. Manoukian PD, Wyatt JR, Leopold DA, Bass EB. Recent trends in utilization of procedures in otolaryngology-head and neck surgery. Laryngoscope. 1997;107(4):472-7. DOI: 10.1097/00005537-1997004000-00009.

3. Freer OT. The correction of deflection of the nasal septum with minimal traumatism. JAMA. 1902;XXXVIII(10):636-42. DOI: 10.1001/ jama.1902.62480100012002b.

4. Killian G, Foster EE. The submucous window resection of the nasal septum. Ann Otorhinolaryngol. 1905;14(2):363-93.

5. Metzenbaum M. Replacement of the lower end of the dislocated carti- 
lage versus submucous resection of dislocated end of the septal cartilage. Arch Otolaryngol. 1929;9(3):282-96. DOI: 10.1001/archotol.1929.00620030300008.

6. Fomon S, Syracuse VR. Plastic repair of the deflected nasal septum. Arch Otolaryngol. 1946;44:141-56.

7. Cottle MH, Loring RM, Fischer GG, Gaynon IE. The maxilla-premaxilla approach to extensive nasal septum surgery. AMA Arch Otolaryngol. 1958;68(3):301-13. DOI: 10.1001/archotol.1958.00730020311003.

8. Hildbrandt T. Principles of modern septoplasty. In: Behrboom H, Tardy ME, eds. Essentials in Septorhinoplasty. Philosophy- Approaches-Technique. Stuttgart-New York: Thieme; 2004, p.112.

9. Kastenbauer ER. Surgery of the internal nose. In: Kastenbauer ER, Tardy ME, eds. Aesthetische und Plastische Chirurgie an Nase, Gesicht und Ohrmuschel. Stuttgart-New York: Thieme; 2005, p.8.

10. Kim DW, Toriumi DM. Open structure rhinoplasty. In: Behrboom H, Tardy ME, eds. Essentials in Septorhinoplasty. Philosophy- ApproachesTechnique. Stuttgart-New York: Thieme; 2004, p.121.

11. Friedman M, Ramakrishna V. Surgical management of septal deformity, turbinate hypertrophy, nasal valve collapse and choanal atresia. In: Bailey BJ, Johnson JT, eds. Head and Neck Surgery - Otolaryngology. Philadel- phia, PA: Lippincott Williams \& Wilkins; 2006, p.323.

12. Rettinger G, Kirsche H. Complications in septoplasty. Facial Plast Surg. 2006;22(4):289-97. DOI: 10.1055/s-2006-954847.

13. Plate S, Asboe S. Blindness as a complication of rhinosurgery. J Laryngol Otol. 1981;95:317-22.

14. Lund VJ, Mackay IS. Staging in rhinosinusitis. Rhinology. 1994;31(4):183-4.

15. Tahery J, Belloso A, Zarod AP. New method for raising the mucoperichondrial flap in septal surgery: microscope-assisted hydrodissection technique. J Laryngol Otol. 2004;118(9):715-6. DOI: 10.1258/0022215042244723.

16. Dubach P, Mantokoudis G, Banz Y, Herrmann G, Caversaccio M. Hydrodissection for subperichondrial septoplasty - an experimental anatomical study. Rhinology. 2010;48(2):195-200. DOI: 10.4193/Rhin09.120.

17. Pons Y, Champagne C, Genestier L, Ballivet de Regloix S. Endoscopic septoplasty: Tips and pearls. Eur Ann Otorhinolaryngol Head Neck Dis. 2015;132(6):353-6. DOI: 10.1016/j.anorl.2015.08.032.

18. Thejas SR, Mohan S. Effectiveness of isolated septal surgeries in nasal septal deviations: A prospective study with reference to the nasal obstruction symptom evaluation scale. Ann Indian Acad Otorhinolaryngol Head Neck Surg. 2019;3(2):63-8. 